\title{
Fabrication of Sensitive Potentiometric Cholesterol Biosensor Based on $\mathrm{Co3O4}$ Interconnected Nanowires
}

\author{
Zafar Hussain Ibupoto, Sami Elhag, Omer Nur and Magnus Willander
}

\author{
Linköping University Post Print
}

\section{Tweet}

N.B.: When citing this work, cite the original article.

Original Publication:

Zafar Hussain Ibupoto, Sami Elhag, Omer Nur and Magnus Willander, Fabrication of Sensitive Potentiometric Cholesterol Biosensor Based on Co3O4 Interconnected Nanowires, 2014, Electroanalysis, (26), 1928-1934.

http://dx.doi.org/10.1002/elan.201400192

Copyright: Wiley-VCH Verlag http://www.wiley-vch.de/publish/en/

Postprint available at: Linköping University Electronic Press

http://urn.kb.se/resolve?urn=urn:nbn:se:liu:diva-112272 


\title{
Fabrication of sensitive potentiometric cholesterol biosensor based on $\mathrm{Co}_{3} \mathrm{O}_{4}$ interconnected nanowires
}

\author{
Zafar Hussain Ibupoto, Sami Elhag*, Omer Nur and Magnus Willander \\ Department of Science and Technology, Campus Norrköping, Linköping University, \\ Norrköping SE 60174, Sweden; E-Mails: zafar.hussain.ibupoto@liu.se; omer.nour@liu.se; \\ magnus.willander@liu.se.
}

* Author to whom correspondence should be addressed; E-Mail: sami.elhag@liu.se; Tel.: +46-11-36-3035; Fax: +46-11-36-3270.

\begin{abstract}
Highly sensitive, selective, reliable and inexpensive cholesterol biosensors are highly demanded for the routine monitoring of cholesterol molecules in order to prevent the heart failure incidents. In this study, $\mathrm{Co}_{3} \mathrm{O}_{4}$ nanostructures are synthesized using polyvinyl pyrrolidone surfactant as a growth template by a low temperature aqueous chemical growth method. The morphology of nanostructures was investigated by scanning electron microscopy and X-ray diffraction techniques. The nanostructures exhibit interconnected nanowires like morphology with interconnected network of nanowires. The nanostructures of $\mathrm{Co}_{3} \mathrm{O}_{4}$ are polycrystalline. The cholesterol oxidase was physically adsorbed on the interconnected nanowires of $\mathrm{Co}_{3} \mathrm{O}_{4}$ for the chemical sensing of cholesterol molecules. The sensor device detected a wide range of cholesterol from $1 \times 10^{-7} \mathrm{M}$ to $1 \times 10^{-3} \mathrm{M}$ concentrations with sensitivity of $-94.031 \mathrm{mV} /$ decade. A detection limit of $0.035 \times 10^{-7} \mathrm{M}$ cholesterol concentration was observed and a fast response time of $10 \mathrm{~s}$ was also noticed. The fabricated device is highly stable, selective, sensitive, reproducible and repeatable. All the collected information about presented cholesterol biosensor indicates its potential application for the monitoring of cholesterol concentrations from human blood serum and real-life samples.
\end{abstract}

Keywords: Biosensor; $\mathrm{Co}_{3} \mathrm{O}_{4}$ interconnected nanowires; cholesterol oxidase; potentiometric response; sensitive 


\section{Introduction}

Cholesterol is a lipid compounds, and present in all the cells of human body [1]. The physiological level of cholesterol in the human serum is around $5.17 \mathrm{mM}$ [2]. The elevated concentration of cholesterol could lead to life threatening diseases such as diabetes, cancer, cardiac, brain vascular, etc... Therefore, the determination of cholesterol concentration in human body is vital task [3-5]. Different analytical tools have been used for the quantification of cholesterol levels including calorimetric, spectroscopic, and electrochemical techniques [68]. Meanwhile, potentiometric sensors are well-known electro-analytical devices over the past five decades. Their versatile chemical selectivity could easily be tuned with lipophilic ionophore [9]. The first potentiometric enzyme sensor was reported in 1969 [10] since then fast advances in the field of potentiometric sensing have been demonstrated e.g. [11-13]. Generally, potentiometric sensors do not require external power source and no current passes during detection; hence they are very attractive for developing sensors for biological systems [12].

Due to emerging of nanotechnology science in the development of novel devices with more selectivity, fast response time and sensitivity has provided a solid platform for the generation of new sensors [14] which could measure accurate concentration of cholesterol. The properties of nanostructures are largely depending on their morphology and size of the nanoparticles $[15,16]$, which in turn play an important role for the sensor fabrication and their performance [17-22]. Among these several nanomaterials, cobalt oxide $\left(\mathrm{Co}_{3} \mathrm{O}_{4}\right)$ nanostructures, the cobalt (II, III) oxide is a p-type magnetic semiconductor. $\mathrm{Co}_{3} \mathrm{O}_{4}$ exhibits spinal structure in which $\mathrm{Co}^{2+}$ ions occupy the tetrahedral sites and $\mathrm{Co}^{3+}$ ions occupy the octahedral sites in the cubic close packed lattices of oxide ions [23]. In addition to this, $\mathrm{Co}_{3} \mathrm{O}_{4}$ has a high isoelectric point (IEP) value $\sim 8$ and it can be little higher when the temperature rises [24] and biocompatibility, since cobalt itself is an essential element for plants and animals (as vitamin B12). The high IEP of $\mathrm{Co}_{3} \mathrm{O}_{4}$ makes it a good matrix to immobilize an enzyme such as cholesterol oxidase having low isoelectric point $(\sim 4.6)$ through electrostatic interaction [19]. $\mathrm{Co}_{3} \mathrm{O}_{4}$ has been used for various applications including heterogeneous catalysts, solid state sensors and electrochemical based device applications [25-31]. Several nanostructures of $\mathrm{Co}_{3} \mathrm{O}_{4}$ such as nanowires/nanorods [31], nanotubes [32], nanocubes [33], nano spheres [34], and nano plates [35] have been fabricated through various growth techniques. $\mathrm{Co}_{3} \mathrm{O}_{4}$ nanocrystals have been synthesized by a solubility method using surfactant 
as growth template [33] and by a combustion method have been used for the synthesis of $\mathrm{Co}_{3} \mathrm{O}_{4}$ nanocrystals [36].

Irrespective of these growth methods, other more facile growth methods including solgel, polyol process, solvothermal, and polymer assisted method, reflux/microwave assisted techniques and low temperature aqueous method have been used to prepare $\mathrm{Co}_{3} \mathrm{O}_{4}$ nanostructures [37-39]. These growth methods can produce high quality and diverse morphologies of cobalt oxide nanostructures; however the high temperature $\left(>100{ }^{\circ} \mathrm{C}\right)$ of these growth methods limits the growth of cobalt oxide nanostructures on organic flexible substrates. The hydrothermal growth method is widely used for the synthesis of cobalt oxide nanostructures on several substrates particularly of its low temperature $\left(<100{ }^{\circ} \mathrm{C}\right)$, simple methodology, non-toxicity, inexpensive and yields high amount of desired nanomaterial. At large scale, $\mathrm{Co}_{3} \mathrm{O}_{4}$ nanowires have been synthesized by low temperature aqueous chemical growth method [40]. The poly (vinyl pyrrolidone) (PVP) was used as a template for the growth of $\mathrm{Co}_{3} \mathrm{O}_{4}$ nanostructures in the present study. Several parameters such as reproducibility, stability, repeatability and selectivity were investigated and discussed in detail.

This study describes the synthesis of cobalt oxide interconnected nanowires using PVP surfactant as a growth template by hydrothermal method on a gold coated glass substrate. The morphology was studied by the scanning electron microscopy and crystal structure was investigated by X-ray diffraction technique. The cholesterol oxidase was immobilized on the $\mathrm{Co}_{3} \mathrm{O}_{4}$ interconnected nanowires for the development of highly sensitive cholesterol biosensor using potentiometry technique.

\section{Experimental Section}

\subsection{Chemicals}

Cobalt chloride hexahydrate $\left(\mathrm{CoCl}_{2} \cdot 6 \mathrm{H}_{2} \mathrm{O}\right)$, cobalt acetate tetrahydrate $\left(\left(\mathrm{CH}_{3} \mathrm{COO}\right)_{2} \cdot \mathrm{Co} \cdot 4 \mathrm{H}_{2} \mathrm{O}\right)$, urea $\left(\mathrm{CH}_{4} \mathrm{~N}_{2} \mathrm{O}\right)$, cholesterol oxidase, cholesterol, d-glucose, ascorbic acid, uric acid, and ferrous chloride tetrahydrate were purchased from Sigma Aldrich Sweden. All chemicals were used of analytical grade. 


\subsection{The fabricated of $\mathrm{Co}_{3} \mathrm{O}_{4}$ nanostructures on a gold coated glass substrate}

A gold layer was coated on a glass substrate was done according to the reported work [41]. The hydrothermal method was used for the synthesis of cobalt oxide nanostructures on the gold coated glass substrate using PVP surfactant as a growth template. Firstly, gold (100 $\mathrm{nm}$ ) coated glass substrates were sonicated in ultrasonic bath for $20 \mathrm{~min}$ in isopropanol, then washed with deionized water and dried with flow of nitrogen gas. A seed layer of cobalt acetate was spin coated on the cleaned gold coated glass substrate using a spin coating technique. The seed deposition process was repeated twice at 2500 r.p.m for 20 s. The seed particles containing substrates were annealed at $120{ }^{\circ} \mathrm{C}$ for $15 \mathrm{~min}$. A growth solution containing equimolar concentration $(0.1 \mathrm{M})$ of cobalt chloride and urea in $100 \mathrm{~mL}$ of deionize water and $300 \mathrm{mg}$ of PVP surfactant was added. PVP was used as the substance that would yield a desired morphology of cobalt oxide nanostructures. After annealing the seed particles containing substrate, it was fixed in Teflon sample holder and dipped with downward face in the growth solution, and then the growth solution was kept in a preheated electric oven for 4$6 \mathrm{~h}$ at $95^{\circ} \mathrm{C}$. After the completion of growth duration, samples containing cobalt hydroxide nanostructures were washed with deionized water and dried at room temperature. Finally, the cobalt oxide nanostructures were obtained after annealing the as-grown samples at $450{ }^{\circ} \mathrm{C}$ for three hours.

The morphology of cobalt oxide nanostructures was investigated by LEO 1550 Gemini field emission scanning electron microscope (SEM) operating at $5 \mathrm{kV}$. The nanocrystalline phase was examined by X-ray powder diffraction (XRD) using a Phillips PW 1729 powder diffractometer combined with $\mathrm{CuK} \alpha$ radiation $(\lambda=1.5418 \AA)$ at a generator voltage of $40 \mathrm{kV}$ and a current of $40 \mathrm{~mA}$.

\subsection{Immobilization of $\mathrm{Co}_{3} \mathrm{O}_{4}$ interconnected nanowires with cholesterol oxidase and electrochemical measurement}

A cholesterol oxidase $(\mathrm{ChOx})$ solution was prepared in $10 \mathrm{mM}$ phosphate buffer of $\mathrm{pH} 7.3$ and immobilized on the $\mathrm{Co}_{3} \mathrm{O}_{4}$ interconnected nanowires through electrostatic physical adsorption method. A stock solution of $50 \mathrm{mM}$ of cholesterol was prepared in few drops of isopropanol and finally mixed with $10 \mathrm{mM}$ phosphate buffer of $\mathrm{pH}$ 7.3. Low concentrations of cholesterol were obtained by dilution. All electrochemical measurements were performed using a Keithley 2400 model at room temperature. 


\section{Results and discussion}

\subsection{The Crystal Structure and Morphological Studies of $\mathrm{Co}_{3} \mathrm{O}_{4}$ Nanostructures}

The crystal structure of annealed $\mathrm{Co}_{3} \mathrm{O}_{4}$ samples was investigated by XRD and the results obtained are shown in Figure 1. It can be seen that the prepared product exhibits sharp diffraction peaks and all the diffraction peaks could be assigned to the nanocrystalline cubic phase of $\mathrm{Co}_{3} \mathrm{O}_{4}$ according to the JCPDS 42-1467 and the high intense peak at $38^{0}$ is assigned to gold substrate. No diffraction peaks were observed other phase of $\mathrm{Co}_{3} \mathrm{O}_{4}$. The morphology of PVP assisted cobalt oxide nanostructures was studied by scanning electron microscopy and distinctive SEM images has shown that nanostructures possess interconnected nanowires like morphology with interconnected network of nanowires. Various SEM images at different magnification were taken as shown in Figure 2(a-c). In the growth of $\mathrm{Co}_{3} \mathrm{O}_{4}$ interconnected nanowires, PVP plays a key role in the controlling the $\mathrm{Co}_{3} \mathrm{O}_{4}$ size and morphology. In this study, PVP was used as a growth template, which resulted in achieved chain structures. In the presence of polymer template, it was possible for $\mathrm{Co}_{3} \mathrm{O}_{4}$ to grow up along these polymeric chains to give nanostructures of $\mathrm{Co}_{3} \mathrm{O}_{4}$. Moreover, PVP has the ability to form a shell surrounding the nanoparticles to prevent them from aggregation together, which would otherwise produce larger nanoparticles due to its steric effect. Previously, the presence of a capping molecule, for example, PVP, was reported [42, 43] to change the surface energy of crystallographic surfaces for enhancing the anisotropic growth of nanostructures. The PVP accumulated on the crystal nuclei cobalt oxide behaved as a growth directing agent.

\subsection{The Chemical Sensing Application of $\mathrm{Co}_{3} \mathrm{O}_{4}$ Interconnected Nanowires for the Detection of Cholesterol Molecules}

The potentiometric response [44] of the proposed cholesterol biosensor (Figure 3 (a)) was measured in phosphate buffer solution of $\mathrm{pH}$ 7.3. The effect of $\mathrm{pH}$ on the ChOx activity has been examined in the range of $\mathrm{pH}$ values between 4 and 8. The range of 7.0-7.5 has been found to yield the best enzymatic activity of the $\mathrm{ChOx} / \mathrm{Co}_{3} \mathrm{O}_{4}$ nanowires / $\mathrm{Au}$ electrode. The chemical sensing of cholesterol molecules was performed at room temperature by immobilizing cholesterol oxidase using physical adsorption method on the $\mathrm{Co}_{3} \mathrm{O}_{4}$ interconnected nanowires. The developed cholesterol biosensor showed a robust response for the dynamic range of cholesterol concentration from $1 \times 10^{-7} \mathrm{M}$ to $1 \times 10^{-3} \mathrm{M}$ with sensitivity 
of $-94.031 \mathrm{mV} /$ decade as shown in Figure 4. The wide range of detection and high sensitivity of presented cholesterol biosensor is attributed to high surface to volume ratio of $\mathrm{Co}_{3} \mathrm{O}_{4}$ interconnected nanowires and their better electrocatalytic properties. The cobalt oxide nanostructures provided a favourable microenvironment for the immobilization of $\mathrm{ChOx}$, which could enhance the catalytic properties of ChOx molecules. This can be deduced from the Michaelis-Menten constant $\left(\mathrm{K}_{\mathrm{m}}\right) . \mathrm{K}_{\mathrm{m}}$ is estimated from Lineweaver-Burke plot and was found to be $0.039 \mathrm{mM}$, which is much smaller than that obtained at other cholesterol biosensors (see Table I). From the calculations a limit of detection of the presented sensor was found to be $0.035 \times 10^{-7} \mathrm{M}$ and a fast response time of $10 \mathrm{~s}$ as shown in Figure 5. The sensing mechanism of developed cholesterol biosensor based on $\mathrm{Co}_{3} \mathrm{O}_{4}$ interconnected nanowires can be described in two different reaction pathways. One way is attributed to the selective response cholesterol oxidase for cholesterol molecules and second way is the direct interaction of cholesterol molecules with the cholesterol oxidase immobilized on the $\mathrm{Co}_{3} \mathrm{O}_{4}$ interconnected nanowires (Figure 3 (b)) which speed up the enzyme substrate reaction even better than that obtained in [22]. In reference [22] they demonstrated a sensor based on $\mathrm{CuO}$ as a good immobilization matrix for $\mathrm{ChOx}$ while here we have used a heterogeneous-catalysis system compromise of $\mathrm{Co}_{3} \mathrm{O}_{4}$ and $\mathrm{ChOx}$ enzyme, we believe that, this system can even acquire improved properties due to a synergistic effect [45]. On the other hand, that might be attributed to impurities and electrostatic formation into the structure upon an addition of a surfactant $[46,47]$. During the ChOx catalytic oxidation reaction at the time of measurement results the product [48]:

$$
\text { Cholesterol }+\mathrm{O}_{2} \rightarrow \text { 5-3-ketosteroid }+\mathrm{H}_{2} \mathrm{O}_{2}
$$

The 5-3-ketosteroid is the intermediate product at the time of reaction and during the isomerization of trans double bond at 5-6 position of steroid ring by intramolecular shifting of proton from 4-6 $\beta$ sites and a stable product 4-3.ketosteroid is produced as shown below in the chemical reaction.

$$
\text { 5-3-ketosteroid (isomerisation) } \rightarrow \text { 4-3-ketosteroid }
$$

The output potential of the proposed cholesterol biosensor could be assigned to the above reaction mechanism and it creates the charge environment on the surface of $\mathrm{ChOx}$ immobilized on the $\mathrm{Co}_{3} \mathrm{O}_{4}$ interconnected nanowires based electrode. The $\mathrm{Co}_{3} \mathrm{O}_{4}$ nanostructures themselves have excellent electrocatalytic properties which further improve 
the enzymatic activity of ChOx along with the presence of quick and direct electron transfer between the various available sites of $\mathrm{ChOx}$ and the surface of $\mathrm{Co}_{3} \mathrm{O}_{4}$ nanostructures.

\subsection{The study of stability, reproducibility, selectivity and repeatability of proposed cholesterol biosensor based on $\mathrm{Co}_{3} \mathrm{O}_{4}$ interconnected nanowires.}

The stability of cholesterol oxidase immobilized $\mathrm{Co}_{3} \mathrm{O}_{4}$ interconnected nanowires based cholesterol biosensor was evaluated. The developed cholesterol biosensor exhibits good acceptable storage stability when it was used for 15 days, and the corresponding potential difference values are shown in Figure 6. The relative standard deviation (RSD) of the electrochemical response was found less than $5.0 \%$ for sensor electrode. This experiment suggested that the cholesterol biosensor could be used for routine monitoring of cholesterol with same sensitivity and reusability for longer period of time. During these experiments the obtained slopes were compared and it was found that sensor has ability to maintain its $95 \%$ sensitivity. This behavior could be assigned to well suited network of interconnected nanowires of $\mathrm{Co}_{3} \mathrm{O}_{4}$ for $\mathrm{ChOx}$ at the time of immobilization and further played a role in enhancing the catalytic properties of $\mathrm{ChOx}$ by $\mathrm{Co}_{3} \mathrm{O}_{4}$ nanostructures. The reproducibility of the proposed cholesterol biosensor was investigated using six individual sensors electrodes in $1 \times 10^{-4} \mathrm{M}$ cholesterol concentration and the results are shown in Figure 7. It can be judged that sensor to sensor response is highly reproducible with a relative standard deviation of $5 \%$. This degree of reproducibility was attributed to the good entrapping of cholesterol oxidase molecules in the interconnected nanowires of $\mathrm{Co}_{3} \mathrm{O}_{4}$. The selectivity is the main parameter for evaluating the performance of sensor device in the presence of common interferents in human blood serum such as $0.5 \mathrm{mM}$ of ascorbic acid, uric acid, glucose, urea, and Fe (II), respectively. The selectivity coefficient $\left(\mathrm{k}_{\mathrm{ij}}\right)$ value was calculated by the fixed-interference method [44] using formula [49]:

$$
a_{i, \min }=k_{i j} a_{j}^{z_{i} / z_{j}}
$$

where: $a_{i, m i n}$ is the detection limit for the cholesterol molecule, all the interferents concentration $\left(\mathrm{a}_{\mathrm{j}}\right)$ are fixed $(0.5 \mathrm{mM})$, and the calculated $\mathrm{K}_{\mathrm{ij}}$ values are found to be and 1.2 $\times 10^{-4}, 1.2 \times 10^{-4}, 7 \times 10^{-6}$, and $7 \times 10^{-6}$, and for ascorbic acid, glucose, uric acid, , and Fe (II) respectively. The result shows a high degree of selectivity towards the detection of cholesterol even in more than the physiological concentrations of each interferent. The high selectivity of 
presented cholesterol biosensor might be due to immobilized cholesterol oxidase towards the selective sensing of cholesterol molecules.

Table I describe some characteristics of the $\mathrm{ChOx} / \mathrm{Co}_{3} \mathrm{O}_{4}$ nanowires/Au cholesterol sensor along with some of those reported in the literature for other enzymatic nanostructured metal oxide electrodes. As can be seen there is a variety of materials used for cholesterol sensing. We have used potentiometric measurements which is easy to use, reliable, accurate, and inexpensive technique in addition to its suitability for biological systems for the analytical determination of cholesterol.

\section{Conclusions}

The surfactant assisted $\mathrm{Co}_{3} \mathrm{O}_{4}$ interconnected nanowires are synthesized on a gold coated glass substrate by hydrothermal method and cholesterol oxidase was entrapped in the interconnected nanowires of cobalt oxide for the chemical sensing of cholesterol molecules. Potentiometric measurements were used for the quantification of cholesterol molecules in the phosphate buffer solution of $\mathrm{pH}$ 7.3. The sensor device exhibited a sensitivity of -94.031 $\mathrm{mV} /$ decade and a fast response time of $10 \mathrm{~s}$. The low limit of detection for cholesterol was found to be $5 \times 10^{-8} \mathrm{M}$. The presented cholesterol biosensor is highly selective towards the detection of cholesterol concentrations and showed no response to common interferents. The high sensitivity and excellent selectivity are combined results of heavy loading of cholesterol oxidase in the interconnected nanowires of $\mathrm{Co}_{3} \mathrm{O}_{4}$ and enhanced catalytic properties of cholesterol oxidase on the sensitive surface of cobalt oxide nanostructures. 


\section{References}

[1] J. W. Baynes, M. H. Dominiczak, Medical Biochemistry, 2nd ed., Elsevier Mosby, Philadelphia, USA, 2005.

[2] J. MacLachlan, A. T. L. Wotherspoon, R. O. Ansell, C. J. W. Brooks, Journal of Steroid Biochemistry and Molecular Biology 2000, 72,169.

[3] M. Nauck, W. Marz, H. Wieland, Clinical Chemistry 2000, 46, 436.

[4] B.Staels, Nature London 2002, 417, 699.

[5] E. Ikonen, Nat. Rev. Mol. Cell Biol. 2008, 9, 125.

[6] W. M. Sperry and F. C. Brand. J. Biol. Chem. 1943, 150, 315-324

[7] T. Nakaminami, S. Kuwabata, H. Yoneyama, Anal. Chem. 1997, 69, 2367.

[8] W. Trettnak, I. Lionti, M. Mascini, Electroanalysis 1993, 5, 753.

[9] E. Bakker, P. Bühlmann, and E. Pretsch, Chem. Rev. 1997, 97, 3083-3132

[10] G. G. Guilbault, J. G. Montalvo, J. Am Chem. Soc 1969, 91, 2164.

[11] B. H. van der Schoot, and P. Bergveld, , Fresenius Z Anal Chem 1988, 330, 335

[12] J. Bobacka, A. Ivaska, and A. Lewenstam. Chem. Rev. 2008, 108, 329-351.

[13] A. Bratov*, N. Abramova, A. Ipatov, Analytica Chimica Acta 2010, 678, 149-159.

[14] P. R. Solanki, A. Kaushik, V. V. Agrawal and B. D. Malhotra, NPG Asia Materials 2011, 3, 17-24; doi:10.1038/asiamat.2010.137.

[15] X. Wang, X.Y. Chen, L.S. Gao, H.G. Zheng, Z. Zhang, Y.T. Qian, J. Phys. Chem. B 2004, 108, 16401-16404.

[16] J. Feng, H.C. Zeng, Chem. Mater. 2003,15, 14 2829-2835.

[17] G. K. Kouassi, J. Irudayaraj, and G. McCarty, Journal of Nanobiotechnology 2005, 3, 1 
[18] S. P. Singh, S. K. Arya, P. Pandey, B. D. Malhotra, S. Saha, K. Sreenivas, and V.Gupta, Appl. Phys. Lett. 2007, 91, 063901.

[19] A. Salimi, R. Hallaj, and S. Soltanian, Electroanalysis, 2009, 21, 2693.

[20] A. A. Ansari, A. Kaushik, P. R. Solanki, and B. D. Malhotra, Electroanalysis, 2009, 21, 965.

[21] A. Kumar, Rajesh, B. D. Malhotra, S. K. Grover, Anal. Chim. Acta 2000, 414, 43.

[22] Z. H. Ibupoto, K. Khun, X. Liu, and M. Willander, Materials Science and Engineering C 2013, 33, 3889-3898.

[23] A. Earnshaw, N. Greenwood, Chemistry of the Elements, 2nd ed.; Publisher ButterworthHeinemann UK, 1997.

[24] S. Kittaka, and T. Morimoto, J. Colloid Interface, 1980, 75, 398-403

[25] Y. Yu, C.H. Chen, J.L. Shui, S. Xie, Angew. Chem. Int. Ed. 2005, 44, 7085-7089.

[26] Y.G. Li, B. Tan, Y.Y. Wu, J. Am. Chem. Soc. 2006, 128, 14258-14259.

[27] T. Maruyama, S. Arai. J. Electrochem. Soc. 1996, 143, 1383-1386.

[28] L. Yan, X. M. Zhang, T. Ren, H. P. Zhang, X. L. Wang, J. S. Suo, Chem. Commun. 2002 860-861. DOI: 10.1039/B201237E.

[29] E. M. Logothesis, R. Park, A. H. Meitzler, K. K. Laud, Appl. Phys. Lett. 1975, 26, 209-211.

[30] J. Wollenstein, M. Burgmair, G. Plescher, T. Sulima, J. Hildenbrand, H. Bottner, I. Sensors Actuators B. 2003, 93, 442-448.

[31] X. Yao, X. Xin, Y. Zhang, J. Wang, Z. Liu, X. Xu, J. Alloys. Compd. 2012, 521, 95-100.

[32] L. H. Hu, Q. Peng, Y. D. Li, J. Am. Chem. Soc. 2008, 130, 16136-16137.

[33] T. He, D. R. Chen, X. L. Jiao, Y. L. Wang, Adv. Mater. 2006, 18, 1078-1082. 
[34] A. M. Cao, J. S. Hu, H. P. Liang, W. G. Song, L. J. Wan, X. L. He, X. G. Gao, S. H. Xia, J. Phys. Chem. B 2006, 110, 15858-15863.

[35] Y. L. Hou, H.S. Kondoh, M.S. Shimojo, T. Kogure, T. Ohta, J. Phys. Chem. B 2005, 109, 19094-19098.

[36] G. Feng, L. Chunzhong, H. Yanjie, Z. Ling. J. Cryst. Growth. 2007, 304, 369-373.

[37] P. Dutta, M.S. Seehra, S. Thota, J. Kumar. J. Phys. Condes. Matter. 2008, 20, 015218015223.

[38] W-M. Zhang, M. Chen, Y-Q. Jiang, Int. Nano. Lett. 2013, 3, 44(1-4).

[39] G. Wang, X. Shen, J. Horvat, B. Wang, H. Liu, D. Wexler, J. Yao. J. Phys Chem C. 2009, 113, 4357-4361.

[40] X.H. Liu, G.Z. Qiu, X.G. Li, Nanotechnology 2005, 16, 3035-3040.

[41] Z.H. Ibupoto, Syed M. Usman Ali, C.O. Chey, K. Khun, O. Nur, Magnus Willander, J. Appl. Phys. 2011, 110, 104702.

[42] W. I. Park, D. H. Kim, S. W. Jung, G.-C. Yi, Appl. Phys. Lett. 2002, 80, 4232-4234.

[43] D. Jimin, L. Zhimin, H. Ying, G. Yanan, H. Buxing, L. Wenjing, Y. Guanying, J. Cryst Growth. 2005, 280, 126-134.

[44] R. P. Buck and E. Linder, Pure \&Appl. Chem. 1994, 66, 2527-2536.

[45] X.-Y. Lang, H. -Y. Fu, C. Hou, G. -F. Han, P. Yang, Y. -B. Liu, and Q. Jiang, Nature Communications, 2013, 4, doi:10.1038/ncomms3169.

[46] X.-G. Wang, Q.-S. Wu, W.-Z. Liu, Y.-P. Ding, Electrochimica Acta 2006, 52, 589-594.

[47] C. Li, D. Zhang, B. Lei, S. Han, X. Liu, and C. Zhou, J. Phys. Chem. B, 2003, 107, 12451-12455.

[48] J. MacLachlan, A. T. L. Wotherspoo, R. O. Ansell, C. J. W. Brooks, J. Journal of Steroid Biochemistry \& Molecular Biology 2000, 72, 169-195.

[49] J. Wang, Analytical electrochemistry, $3^{\text {rd }}$ Ed., John Wiley \& Sons, Inc., Ch. 5, 171, 2006. 


\section{Figure captions}

Figure 1: XRD spectrum of $\mathrm{Co}_{3} \mathrm{O}_{4}$ interconnected nanowires.

Figure 2: SEM images of $\mathrm{Co}_{3} \mathrm{O}_{4}$ interconnected nanowires at different magnifications.

Figure 3: Schematic diagram of (a) an experimental setup of two electrodes system, and (b) the arrangement of the potentiometric cholesterol biosensor.

Figure 4: Calibration curve for the cholesterol biosensor.

Figure 5: Response time curve for the fabricated sensor device.

Figure 6: Stability graph for the fabricated biosensor.

Figure 7: Reproducibility curve for the sensor to sensor response.

Table 1: Characteristics of $\mathrm{ChOx} / \mathrm{Co}_{3} \mathrm{O}_{4}$ nanowires/Au cholesterol sensor along with those reported in some literature for other enzymatic nanostructured metal oxide electrodes. 
Fig. 1:

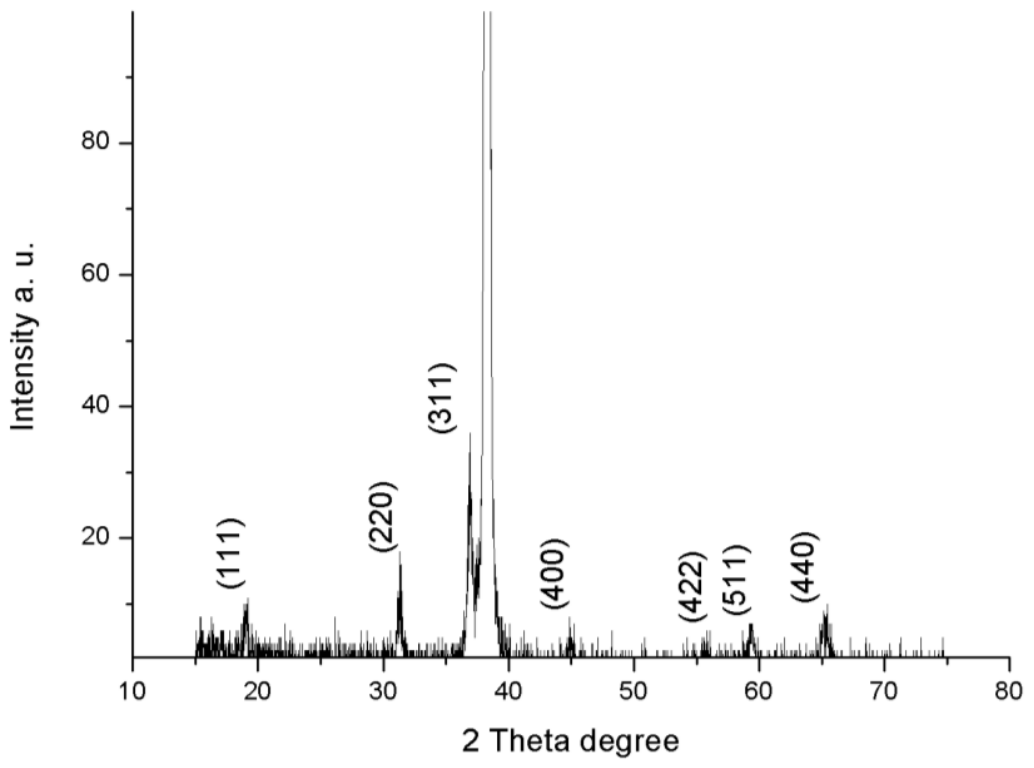


Fig.2:
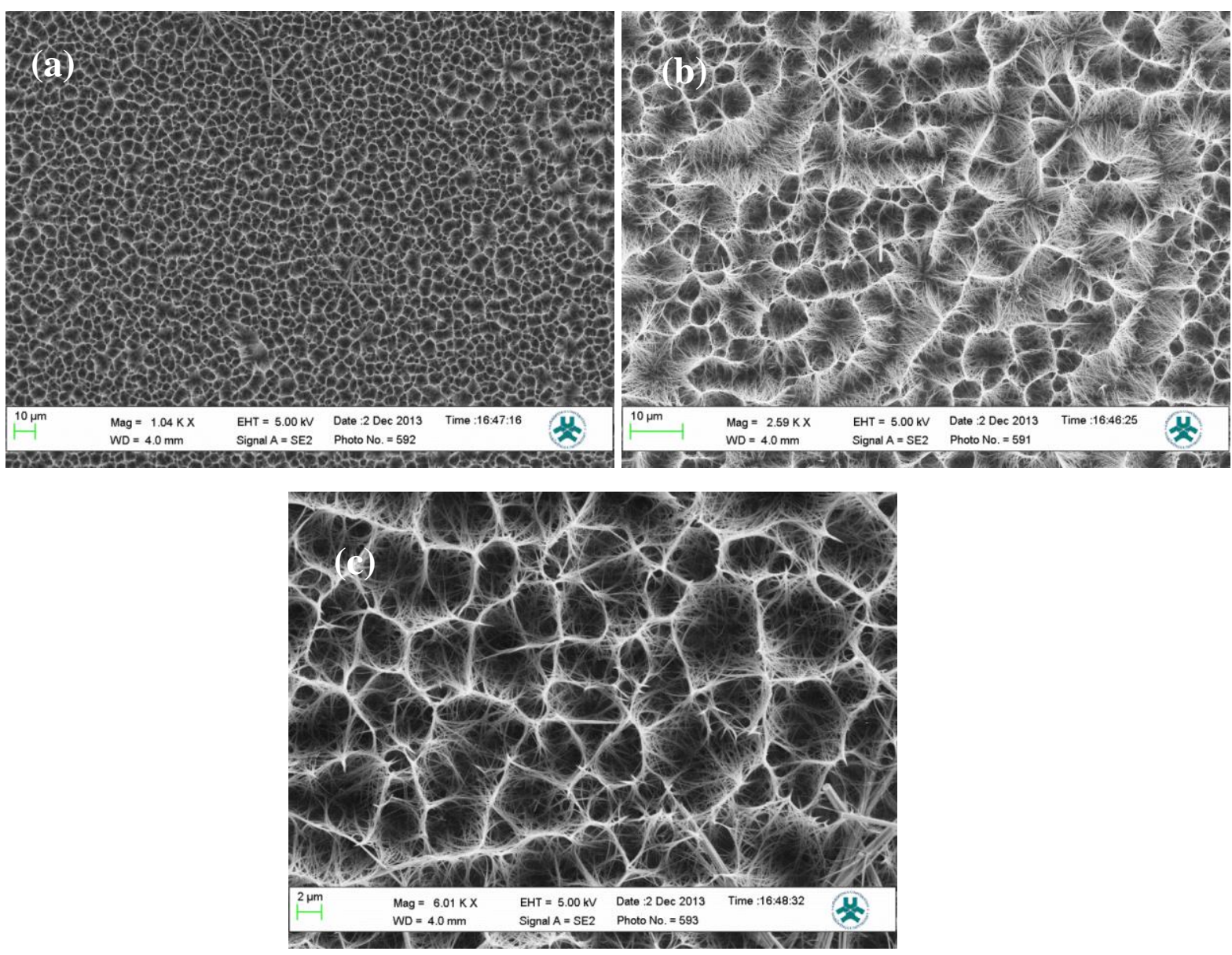
Fig. 3:

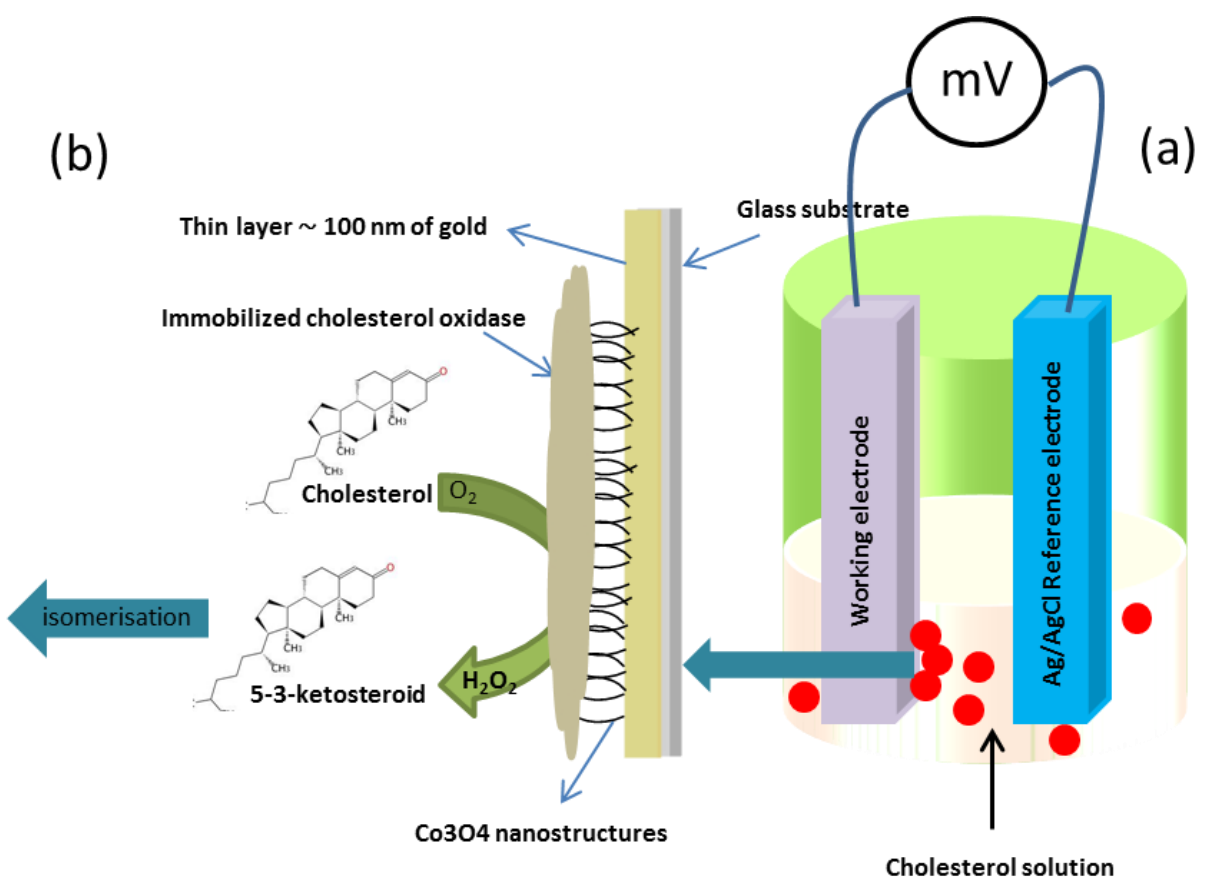


Fig. 4:

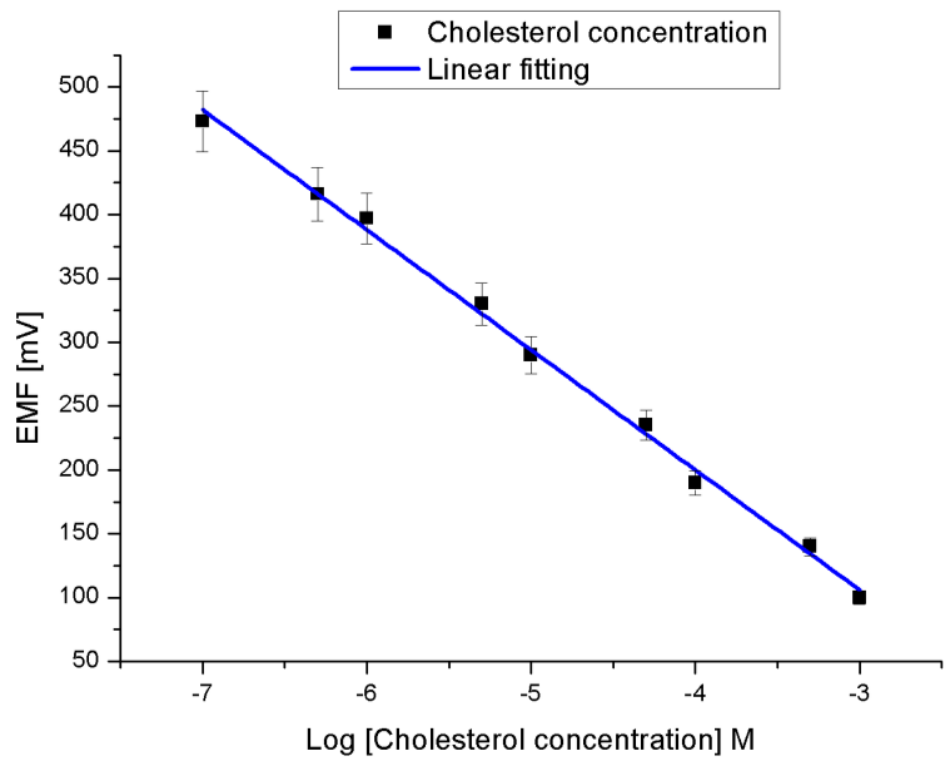


Fig. 5:

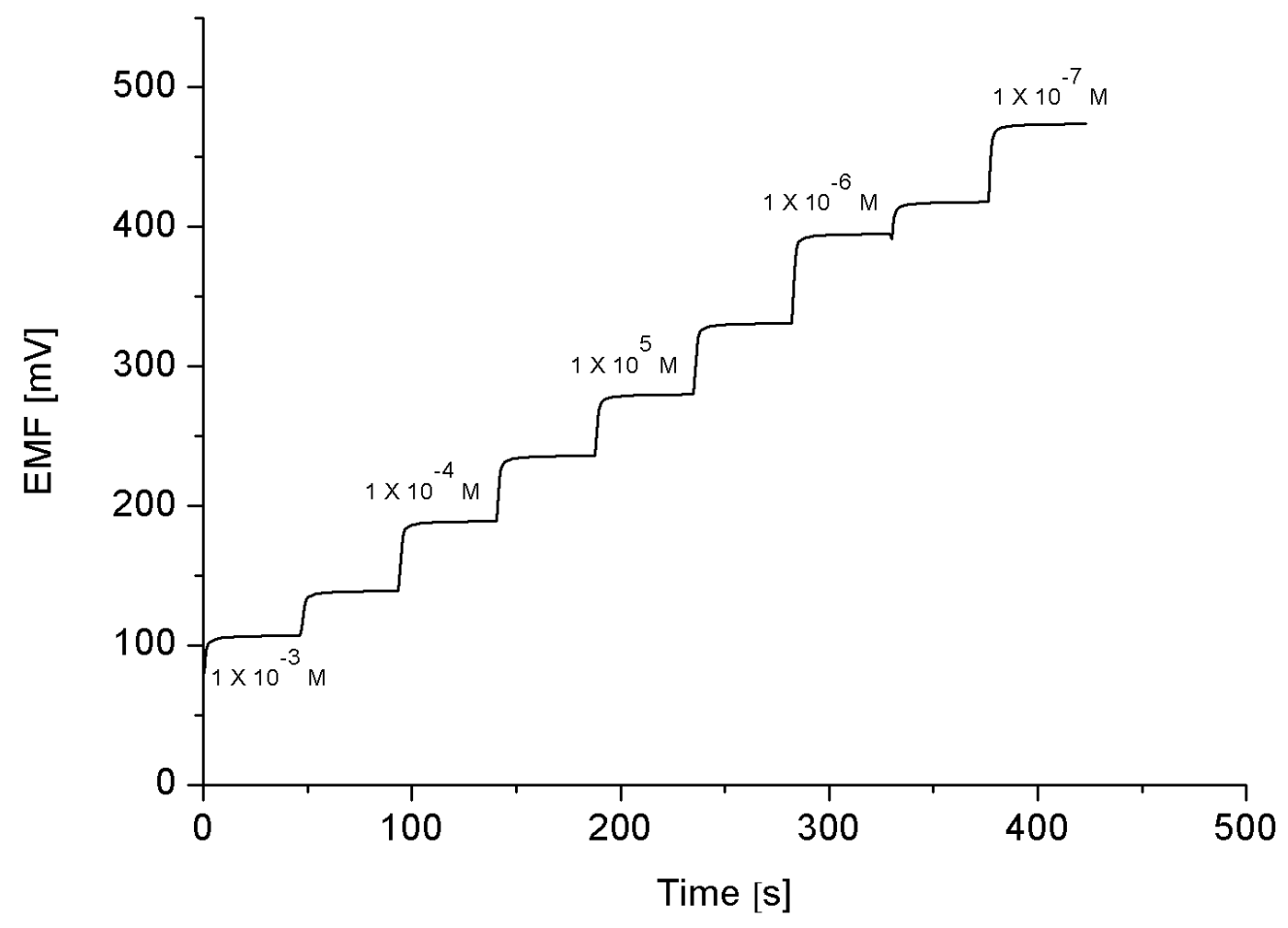


Fig. 6:

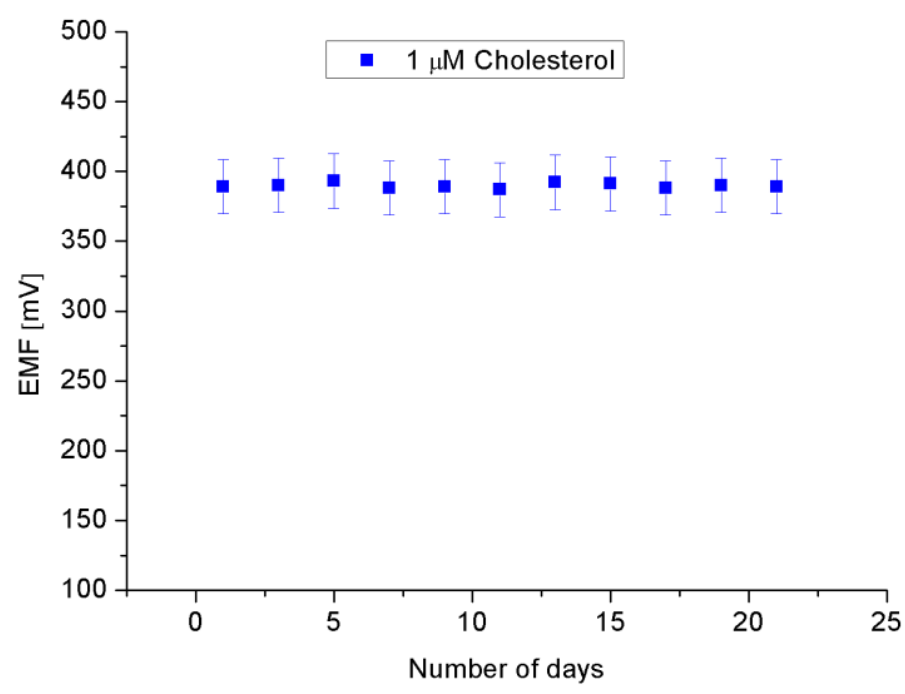


Fig. 7:

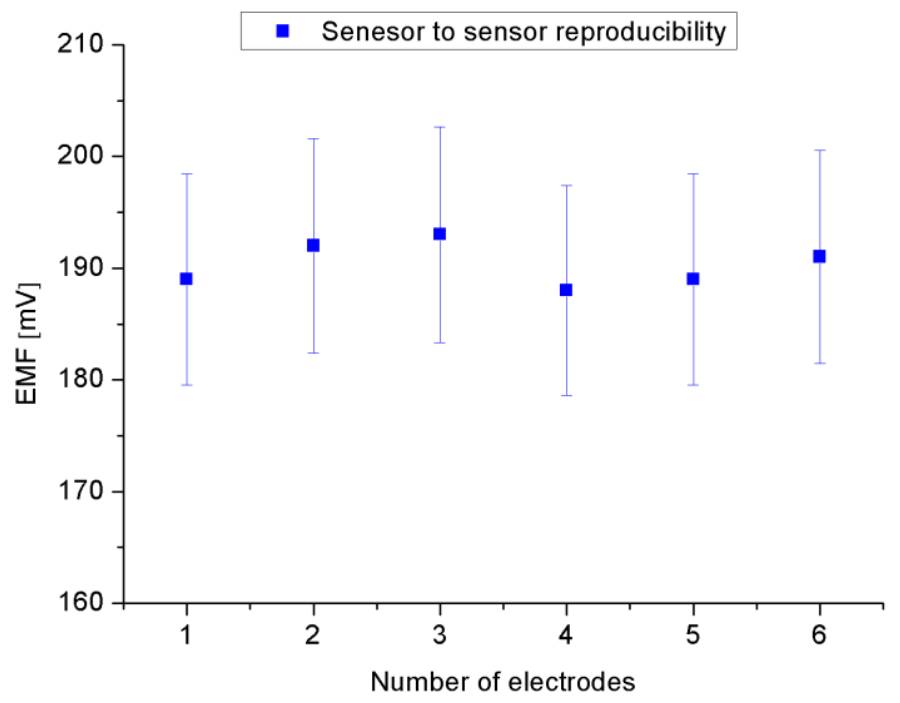


Table I:

\begin{tabular}{|c|c|c|c|c|c|c|}
\hline Working electrode & Technique & $\begin{array}{c}\text { Linearity } \\
{[\mathrm{M}]}\end{array}$ & LOD $[\mathbf{M}]$ & $\mathbf{K m}[\mathbf{M}]$ & Sensitivity & $\begin{array}{c}\text { Response } \\
\text { time [s] }\end{array}$ \\
\hline $\begin{array}{c}\text { ChOx/ Iron } \\
\text { nanoparticales [17] }\end{array}$ & Spectrophotometric & $\begin{array}{c}1.3 \times 10^{-3} \\
-5.2 \times 10^{-3}\end{array}$ & - & $0.45 \times 10^{-3}$ & - & - \\
\hline $\begin{array}{c}\mathrm{ChOx} / \mathrm{ZnO} \\
\text { nanoporous thin film } \\
\text { /Au [18] }\end{array}$ & Electrochemical & $\begin{array}{c}0.65 \times 10^{-3} \\
-10.34 \times \\
10^{-3}\end{array}$ & - & $2.1 \times 10^{-3}$ & - & - \\
\hline $\begin{array}{c}\text { ChOx/ cobalt oxide } \\
\text { nanomaterials/ Glassy } \\
\text { Carbon [19] }\end{array}$ & $\begin{array}{c}\text { Flow injection } \\
\text { analysis }\end{array}$ & $\begin{array}{r}4.2 \times 10^{-6} \\
-50 \times 10^{-6}\end{array}$ & $4.2 \times 10^{-6}$ & 0.49 & $\begin{array}{c}43.5 \mathrm{nA} \\
\mathrm{mM}^{-1} \mathrm{~cm}^{-2}\end{array}$ & 15 \\
\hline $\begin{array}{l}\text { ChOx/ chitosan-tin } \\
\text { oxide } \\
\text { nanobiocomposite/ } \\
\text { ITO [20] }\end{array}$ & Amperomtric & $\begin{array}{c}0.26 \times 10^{-3} \\
-10.36 \times \\
10^{-3}\end{array}$ & $0.13 \times 10^{-3}$ & $3.8 \times 10^{-3}$ & $\begin{array}{c}34.7 \\
\mathrm{~mA} / \mathrm{mg} \mathrm{dL} \\
{ }^{-1} \mathrm{~cm}^{2}\end{array}$ & 5 \\
\hline $\begin{array}{c}\mathrm{ChOx} / \mathrm{Fe}_{3} \mathrm{O}_{4} \\
\text { nanoparticles [21] }\end{array}$ & Amperomtric & $\begin{array}{c}1.3 \times 10^{-3} \\
-5.2 \times 10^{-} \\
3\end{array}$ & $0.5 \times 10^{-3}$ & $0.45 \times 10^{-3}$ & - & 50 \\
\hline $\begin{array}{c}\mathrm{ChOx} / \mathrm{CuO} \\
\text { nanowires/Au [22] }\end{array}$ & Potentiomtirc & $\begin{array}{c}5 \times 10^{-6}-5 \\
\times 10^{-3} \\
\end{array}$ & $1 \times 10^{-6}$ & - & $\begin{array}{c}33.88 \\
\mathrm{mV} / \text { decade } \\
\end{array}$ & 10 \\
\hline $\begin{array}{c}\mathrm{ChOx} / \mathrm{Co}_{3} \mathrm{O}_{4} \\
\text { nanowires/Au [this } \\
\text { work] }\end{array}$ & Potentiomtirc & $\begin{array}{c}1 \times 10^{-7}-1 \\
\times 10^{-3}\end{array}$ & $0.035 \times 10^{-7}$ & $\begin{array}{c}0.039 \times 10^{-} \\
3\end{array}$ & $\begin{array}{c}-94.031 \\
\mathrm{mV} / \text { decade }\end{array}$ & 10 \\
\hline
\end{tabular}

